\title{
Impact of the thickness of Nickel oxide film for nitrogen dioxide gas sensing Applications
}

\author{
Ehssan S. Hassan \\ Physics Department, Science \\ Faculty, University of Al- \\ Mustansiriyah, Baghdad, Iraq \\ ehsanphysicyan@uomustansiryah.edu.iq
}

\author{
Marwa Abdul Muhsien Hassan \\ Physics Department, Science Faculty, \\ University of Al- Mustansiriyah, \\ Baghdad, Iraq \\ marwamedicalphysics@gmail.com
}

Sabah J. Mezher

Physics Department, Science

Faculty, University of Al-

Mustansiriyah, Baghdad, Iraq

sabah.j.m@uomustansiryah.edu.iq
Firas S. A. Ameer

\author{
Physics Department, Science \\ Faculty, University of Al- \\ Mustansiriyah, Baghdad, Iraq \\ firasalaraji@uomustansiryah.edu.iq
}

\begin{abstract}
Nickel oxide (NiO) thin films were formed by $R F$ reactive magnetron sputtering onto glass substrates. The Argon and Oxygen partial pressure were $\left(3.2 \times 10^{-3}\right.$ torr) and $\left(2.12 \times 10^{-2}\right.$ torr $)$ respectively at room temperature. The thickness of the films deposited was in the range of 50-150 nm. The thickness necessity structural, electrical and sensing properties of (NiO) films were methodically examined. X-ray diffraction method which shows polycrystalline landscape with preferred reflection peak at (200) plane. Scanning electron microscope analysis revealed that the growth of nanorods in all the films. The gas sensitivity of nitrogen dioxide gas was (67\%). It was observed that the gas sensitivity for (NiO) films was increased as film thickness increases.
\end{abstract}

Keywords: magnetron sputtering, Nickel oxide, Nitrogen dioxide, Dynamic resistance, Sensitivity.

\section{INTRODUCTION}

Nickel oxide $(\mathrm{NiO})$ is the most exhaustively investigated transitional Metal oxide. It is a $\mathrm{NaCl}$ P-type antiferromagnetic oxide semiconductor. It offers promising candidature for many applications such as solar thermal absorber [1], catalyst for $\mathrm{O}_{2}$ evolution [2], photoelectrolysis [3], electrochromic device [4], and functional sensor layers for chemical sensors [5] These films have been fabricated using various physical and chemical vapor deposition techniques such as thermal oxidation of nickel [6], chemical bath deposition [7], spray pyrolysis [8], sol-gel process [9], electron beam evaporation [10], atomic layer deposition [11], pulsed laser deposition [12], metal organic chemical vapor deposition [13], molecular beam epitaxial [14], and DC [15] and RF magnetron sputtering and electrodeposition [16], Among these methods, reactive sputtering is the most extensively used. Researchers [17] have been carried out on the dependence of film properties on sputtering parameters. Numerous reference data and previous studies [18] have demonstrated that superior electric and optical properties of $\mathrm{NiO}$ films can be obtained by reactive sputtering with a sputtering pressure in the range $0.1-1 \mathrm{~Pa}$ and in a pure oxygen atmosphere using a heated substrate. The increase in surface area and the quantum confinement effects have made nanostructured materials are quite distinct from their bulk form in both electrical and optical properties various one-dimensional structures of $\mathrm{NiO}$, such as nanowires, nanorods, and Nanobelts, have attracted much attention [19]. Among these deposition techniques, magnetron sputtering is industrially adopted thin films preparation method because of the advantages in the generation of uniform and large area films. The physical properties of the sputtering films depend mainly on the process parameters such as oxygen partial pressure, sputter power, substrate temperature, substrate bias, thickness and post deposition annealing The influences of film thickness on the structural, optical, and electrical properties of thin films are very important. Many reports on the effect of size on thin films of various materials have been published [20]. However, only a few works on the dependence of the properties nickel oxide films on film thickness have been published [21].

\section{METHODS AND MATERIALS}

Thin films of nickel oxide were formed onto well-cleaned glass substrates (Super River w. Germany) held at temperature range $40^{\circ} \mathrm{C}-50^{\circ} \mathrm{C}$ which is the sputter chamber temperature by RF magnetron sputtering method. Metallic nickel target (99.99\% pure supplied by Nuclear Fuel Complex, India) with $50 \mathrm{~mm}$ diameter and $3 \mathrm{~mm}$ thickness was used as sputter target for deposition of the films in the sputter dawn configuration. The deposition rate kept at $(0.1$ - 0.2) $\AA /$ sec by the deposition rate and thickness controlled by crystal sensor (FTM-2000). The distance between the target and the substrate was $(100 \mathrm{~mm})$. The sputter chamber was evacuated to the base pressure of $4.1 \times 10^{-6}$ torr employing molecular devotion and turbo combination. The pressure in the sputter chamber was measured with digital Pirani - Penning gauge (adixen ACS 2000) combination. Argon and oxygen (99.999\% purity) were used as sputter and reactive gasses for deposition of the films. Individual Argon and Oxygen gasses penetrate to the chamber with gas mass flue controller (Ailcat scientific) controllers were employed to admit these gasses in required quantities in the sputter chamber. The Argon and Oxygen partial pressure were $\left(3.2 \times 10^{-3}\right.$ torr $)$ and $\left(2.12 \times 10^{-2}\right.$ torr $)$ respectively. Radio frequency $(13.5 \mathrm{KHz}) \mathrm{RF}$ power (TORR INTERNATIONAL, INC.CRC600) used to feed the sputter target of $200 \mathrm{~W}$. The crystal structure of deposited films was identified by the X-ray diffraction (XRD) (shimadzo 62000 , with cuk ${ }_{\alpha}$ radiation having wavelength $\lambda=0.15406 \mathrm{~nm}$ ) technique. The surface microstructure was studied by ( $\mathrm{S}$ 4160) Hitachi (college of engineering and communications, iran-Tehran) scanning electron microscopy (SEM).

\section{RESULTS AND DISCUSSIONS}

\section{Structural reading of Nickel Oxide Films:}

X-ray diffraction pattern of $\mathrm{NiO}$ films prepared by $\mathrm{RF}$ reactive magnetron sputtering with different thickness $(50$, 100 and 150) $\mathrm{nm}$ at (50-60) ${ }^{\circ} \mathrm{C}$ is shown in figure (1) which illustrate that all sample deposited were polycrystalline nature [22] consisting nickel oxide cubic phase with sharp and very fine peaks indicate a good crystallization and the 
major peak is along (200) plane at $2 \theta=42.98^{\circ}$. This is for cubic crystal structure according to ASTM card [No.00-0471049][23]. Minor small peaks along (111) and (220) planes corresponding to the angles $2 \theta=37.23^{\circ}$ and $2 \theta=62.34^{\circ}$ respectively for thickness $50 \mathrm{~nm}$, and only (111) reflection for both thickness $100 \mathrm{~nm}$ and $150 \mathrm{~nm}$. It's observed that the higher intensity in the direction of (200) plane is for the thickness 150 that indicates that enhanced the crystallinity [24].

The lattice constant (a) was calculated by equation (2).

$\mathrm{a}=\mathrm{d} /\left(\mathrm{h}^{2}+\mathrm{k}^{2}+\mathrm{l}^{2}\right) 1 / 2$

$\mathrm{a}=$ lattice constant $(\mathrm{nm})$.

$\mathrm{d}=$ inter planer distance $(\mathrm{nm})$.

$(\mathrm{hkl})=$ miller indices

Table (1) shows lattice constant values that measured from XRD pattern for nanostructure $\mathrm{NiO}$ films and theoretical lattice constant values of ASTM standard card which shows good agreement with those reported earlier by [25]. The peak intensity increase as the film thickness increase, this due to the peak intensity and crystalline are associated with the crystallinity of the deposited films [26]. According to crystal growth mechanism, the crystal orientation of the film is determined by the growth of the nuclei in the deposition of the oxide film, the film initially nucleated in a random orientation. When the film grows from the initial nuclei, the crystal plane of the nuclei with minimum surface free energy may remain parallel to the film surface because of the growth rate of the crystal plane with a minimum surface free energy another crystal plan [27]. The deposition controls processes that including controlling the deposition rate to limits close to $0.1-0.3$ (Álsec.) Advantages to controlling the amount of the thickness of the film which is a key parameter, especially in the Field of nanotechnology. Also reaching necessary vacuum to $10-6$ torr and high purity of used materials leading to achieve high crystalline materials [28]. The Crystallite size (D) has been calculated by Schere's equation (2):

$D=K \lambda / \beta \cos \theta$

$\lambda=$ wavelength of the copper X-ray source which was equal to $(1.5406 \AA$ )

$\beta=$ FWHM in radian.

$\Theta=$ Bragg's diffraction angle

It was found in nanoscale and estimated about $22 \mathrm{~nm}$ $25 \mathrm{~nm}$, as the film thickness increase from $(50-150) \mathrm{nm}$. The enhancement of the crystallinity, which gives Crystallite size with nanoscale, through controlling sputter power and deposition rate with small values led to decreases the FWHM value [29]. Figure (2) shows the Crystallite size and FWHM values varieties with a thickness of $\mathrm{NiO}$ film the results are shown in Table (1). Microstrain $(\varepsilon)$ which has been valued from equation (3):

$\varepsilon=\beta \cos \theta / 4$

is caused during the growth of the film and will be raised from stretching or compression in the lattice. The Microstrain $(\varepsilon)$ reduction caused by varying displacement of the atom with respect to their reference lattice position [30]. Figure (2) shows the Microstrain in the films decreases with the increases in the film thickness, which may cause the increases in the crystallinity of the film [25]. Dislocation density $(\delta)$ is an imperfection in the crystal associated with the registry of the lattice in one part of the crystal with another part. The dislocation density $(\delta)$ has been calculated by using the equation (4) $\delta=1 / D 2$

Figure (2) shows the dislocation density decreases as the thickness increases [31]. The results of Microstrain and dislocation density values are shown in Table (1).

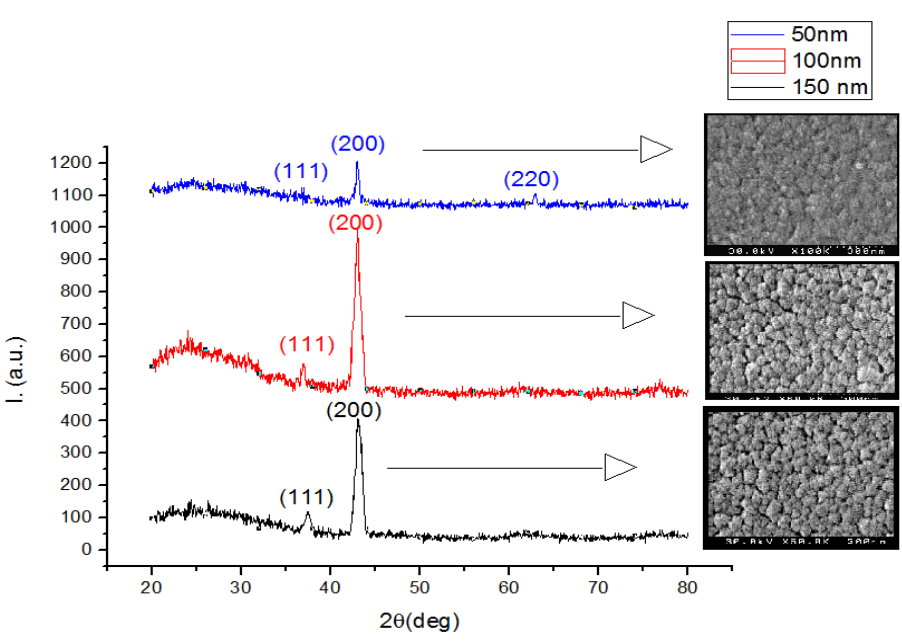

Figure 1: XRD Pattern of Nickel Oxide Films Deposited by RF Reactive Magnetron Sputtering

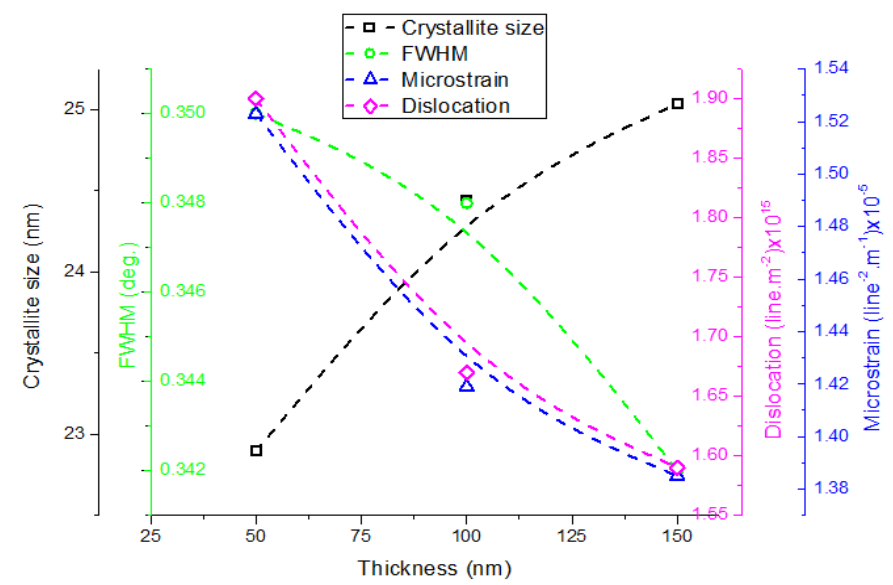

Figure 2: Crystallite, FWHM, Microstrain and Dislocation Density Variation With thickness for NiO Deposited by RF Reactive Magnetron Sputtering. 
Table 1: Structural Parameters of $\mathrm{NiO}$ Thin Films Prepared RF. Sputtering .

\begin{tabular}{|c|c|c|c|c|c|c|c|c|c|c|}
\hline \multirow{2}{*}{$\begin{array}{c}\text { Thickness } \\
\text { (nm) }\end{array}$} & \multirow{2}{*}{$\begin{array}{l}\text { (hkl) } \\
\text { plane }\end{array}$} & \multirow{2}{*}{$\begin{array}{c}F W H M \\
\text { (deg.) }\end{array}$} & \multicolumn{2}{|c|}{$2 \theta$} & \multirow{2}{*}{$\begin{array}{l}X R D \\
d\left(A^{\theta}\right)\end{array}$} & \multirow{2}{*}{$\boldsymbol{I}_{o}$} & \multirow{2}{*}{$\begin{array}{c}\text { Crystallite } \\
\text { size } \\
D(\mathrm{~nm})\end{array}$} & \multirow{2}{*}{$\begin{array}{c}\text { Lattice } \\
\text { Constant } \\
\text { (nm) }\end{array}$} & \multirow{2}{*}{$\left(\begin{array}{c}\text { Microstrain } \\
{\left.\text { (ine } e^{-2} \cdot m^{-1}\right) \times}_{10^{-5}}\end{array}\right.$} & \multirow{2}{*}{$\begin{array}{c}\text { Dislocation } \\
\text { density }(\delta) \\
\left(\text { ine. } m^{-2}\right) \times 10^{15}\end{array}$} \\
\hline & & & $X R D$ & ASTM & & & & & & \\
\hline \multirow{3}{*}{50} & (200) & 0.374 & 42.98 & 43.27 & 0.208 & 100 & 22.894 & 0.4174 & 1.523 & 1.90 \\
\hline & (111) & 0.300 & 37.40 & 37.42 & 0.213 & 6 & - & - & - & - \\
\hline & (220) & 0.482 & 62.85 & 62.78 & 0.408 & 5 & - & - & - & - \\
\hline \multirow{2}{*}{100} & (200) & 0.350 & 43.31 & 43.27 & 0.210 & 100 & 24.438 & 0.4204 & 1.419 & 1.67 \\
\hline & (111) & 0.421 & 37.23 & 37.42 & 0.242 & 12 & - & - & - & - \\
\hline \multirow{2}{*}{150} & (200) & 0.342 & 42.35 & 43.27 & 0.208 & 100 & 25.036 & 0.4170 & 1.385 & 1.59 \\
\hline & (111) & 0.300 & 37.04 & 37.42 & 0.356 & 5 & - & - & - & - \\
\hline
\end{tabular}

\section{Scanning Electron Microscope (SEM)}

The morphology of $\mathrm{NiO}$ nanostructures film prepared by RF-reactive magnetron sputtering method is characterizes by SEM images. Figures (3) show the typical SEM images of the prepared $\mathrm{NiO}$ nanostructures films at a different thickness $(50,100$ and 150) $\mathrm{nm}$ respectively, homogeneous distribution, very smooth and the crystallites are very fine. No large particles can be found from SEM image. Particle size increases from $45 \mathrm{~nm}$ to $60 \mathrm{~nm}$ when the thickness rose from $50 \mathrm{~nm}$ to $100 \mathrm{~nm}$ and nanorods growth perpendicularly with diameter $85 \mathrm{~nm}$ and the surface becomes more porous. When the thickness is further increased to $150 \mathrm{~nm}$ the Nano grains size increases to 70 $\mathrm{nm}$. That is good agreement with XRD measurement for undoped nickel oxide nanostructure films.
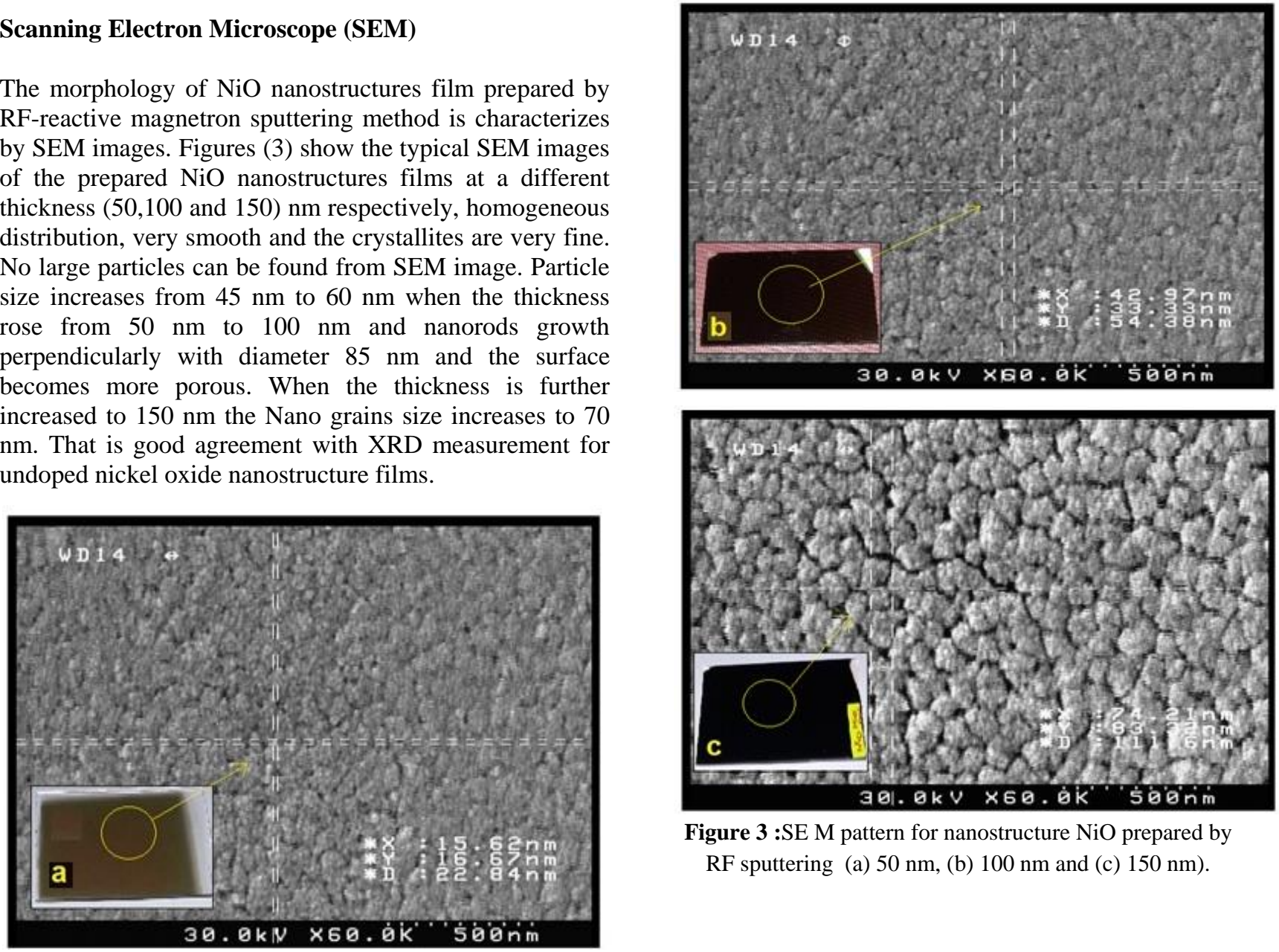

Figure 3 :SE M pattern for nanostructure $\mathrm{NiO}$ prepared by RF sputtering (a) $50 \mathrm{~nm}$, (b) $100 \mathrm{~nm}$ and (c) $150 \mathrm{~nm}$ ).

Gas Sensing Properties:

Nitrogen dioxide, $\mathrm{NO}_{2}$, is one of the most dangerous gasses emitted from burning of the exhaust of cars engines, home heaters, furnaces, plants [32]. 


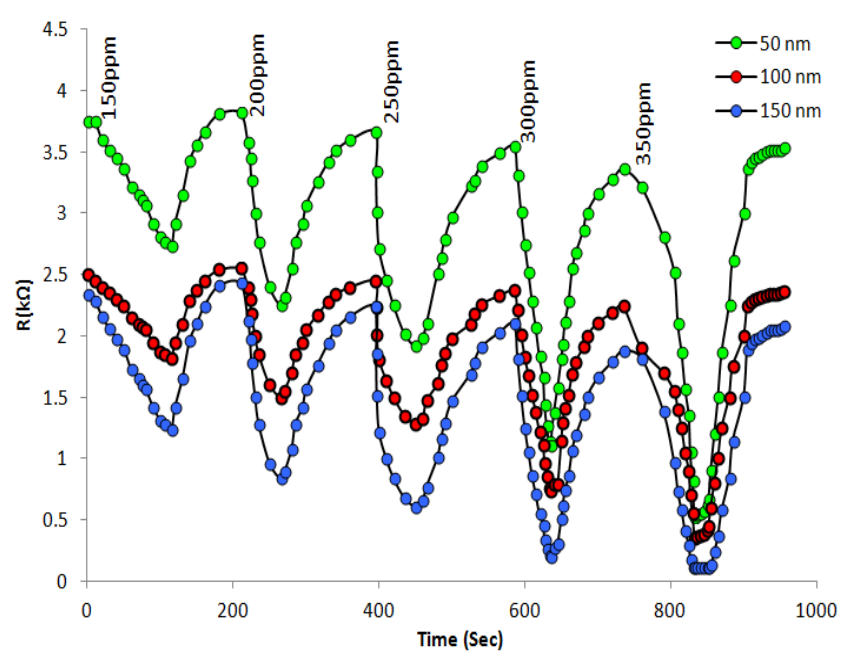

Figure 4: A Dynamic Resistance Change of NiO Films for Different Concentrations of $\mathrm{NO}_{2}$ Gas and Different Thicknesses at an Operating Temperature of $150^{\circ} \mathrm{C}$.

Therefore the development of sensors that are tough small size, long lifetime, and quick in response and with sufficient sensitivity for the detection of nitrogen dioxide in low concentrations, in the environment is so important and needed. The surface morphology and particle size is the key variables in the sensing properties of Metal oxide gas sensors and are mostly organized by the adsorbed oxygen molecules, obviously increasing the surface-tovolume ratio or enhancing the surface adsorption which will increase the resistance change and improve the sensitivity [33]. It is known for many years that the adsorption-dependent electrical properties of metal oxide semiconductors are often sensitive to much gaseous ambient. The gas sensing properties of copper-doped and pure $\mathrm{NiO}$ nanostructures for $\mathrm{NO}_{2}$ as oxidizing gas and hydrogen as reduced gas were studied as a function of the operation time at operation temperature $150^{\circ} \mathrm{C}$. Figure (4) show the dynamic resistance change of $\mathrm{NiO}$ films prepared by RF reactive magnetron sputtering method with different thickness $(50,100$ and 150$) \mathrm{nm}$, exposure to different concentrations of $\mathrm{NO}_{2}$ gas (150, 200, 250, 300 and 350) ppm. It's obvious that lowest resistance was for the samples of $150 \mathrm{~nm}$. Which can be related to the highest roughness obtained from AFM analysis and also due to the high surface area and porosity confirmed from data obtained from the SEM image and also from the electrical resistance that shows the lowest resistance for the film of $150 \mathrm{~nm}$ thickness. All the samples showed p-type semiconductor performance (decreasing in resistance when exposing to oxidize gas) and the resistance of the films decrease with increasing of $\mathrm{NO}_{2}$ concentration inside the chamber [34, 35], this can explain as the electrons are taken from ionized donors through conduction band and the density of majority charge carriers (holes) at the gas-solid interface is increased. This leads to the decreases of a potential barrier for electrons with increasing of the oxygen ions density on the surface. The depletion layer and potential barrier lead to the decreasing of the electrical resistivity value this value is strongly dependent on the concentration of adsorbed oxygen ions of the surface [36]. Introducing the $\mathrm{NO}_{2}$ ambient will change the concentration of these ions and decrease the resistance. The sensitivity can be calculated from equation (5):

Sensitivity $=\Delta R / R_{a}=\left(R_{a}-R_{g} / R_{a}\right) \times 100 \%$

$R_{a}=$ resistance of the film sensor in air presence.

$R_{g}=$ resistance of the film sensor in gas presence. And plotted as a function of gas concentration (ppm) as shown in figure (5). The sensitivity percentage value for $\mathrm{NiO}$ films to nitrogen dioxide gas with different thickness, found to increases with the increasing of film thickness and the highest sensitivity value, is $67 \%$ for $350 \mathrm{ppm}$ gas concentration of $\mathrm{NO}_{2}$ is obtained for the film of $150 \mathrm{~nm}$ thickness at operation temperature $150^{\circ} \mathrm{C}$. The sensitivity of the metal oxide semiconductor sensor is mainly determined by the interaction between the target gas and the surface of the sensor. The greater surface area of the materials that showed in AFM measurements becomes a stronger interaction between the adsorbed gasses and the sensor surface, i.e. higher gas sensing sensitivity.

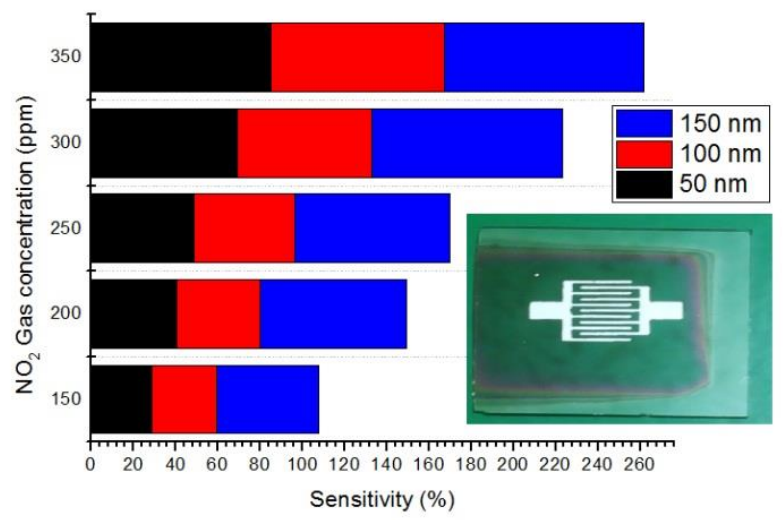

Figure 5: Percentage Sensitivity of NiO Films for Different Concentrations of $\mathrm{NO}_{2}$ Gas and Different Thicknesses at $150{ }^{\circ} \mathrm{C}$ Operating Temperature.

Figure (6) shows the response time, which is found to decrease from (140 to about 60) sec. as the gas concentration increasing, the decreasing in response time may be due to the large availability of vacant sites on thin films for gas adsorption [37]. The response time values are found convergent for all $\mathrm{NiO}$ films to $\mathrm{NO}_{2}$ gas, while, figure (7) shows the increasing in recovery time from (70 to 140) sec. as the $\mathrm{NO}_{2}$ gas concentration increases, this increasing due to the saturation of the sensor by the target gas furthermore the change in the structural properties that could take place by the operating temperature. 


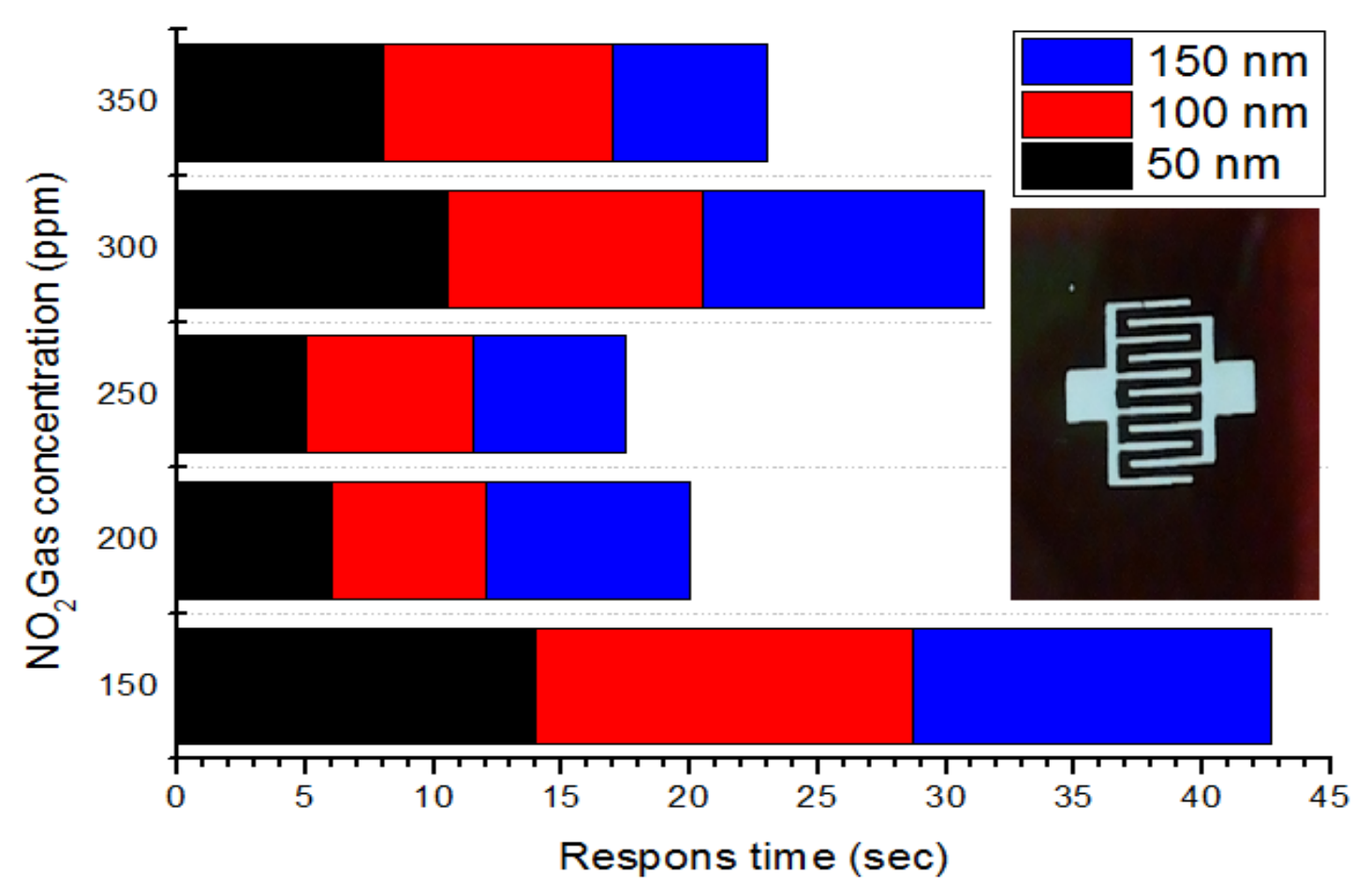

Figure 6: Response Time of $\mathrm{NiO}$ Films for Different Concentrations of $\mathrm{NO}_{2} \mathrm{Gas}$ and Different Thicknesses at $150^{\circ} \mathrm{C}$ Operating Temperature.

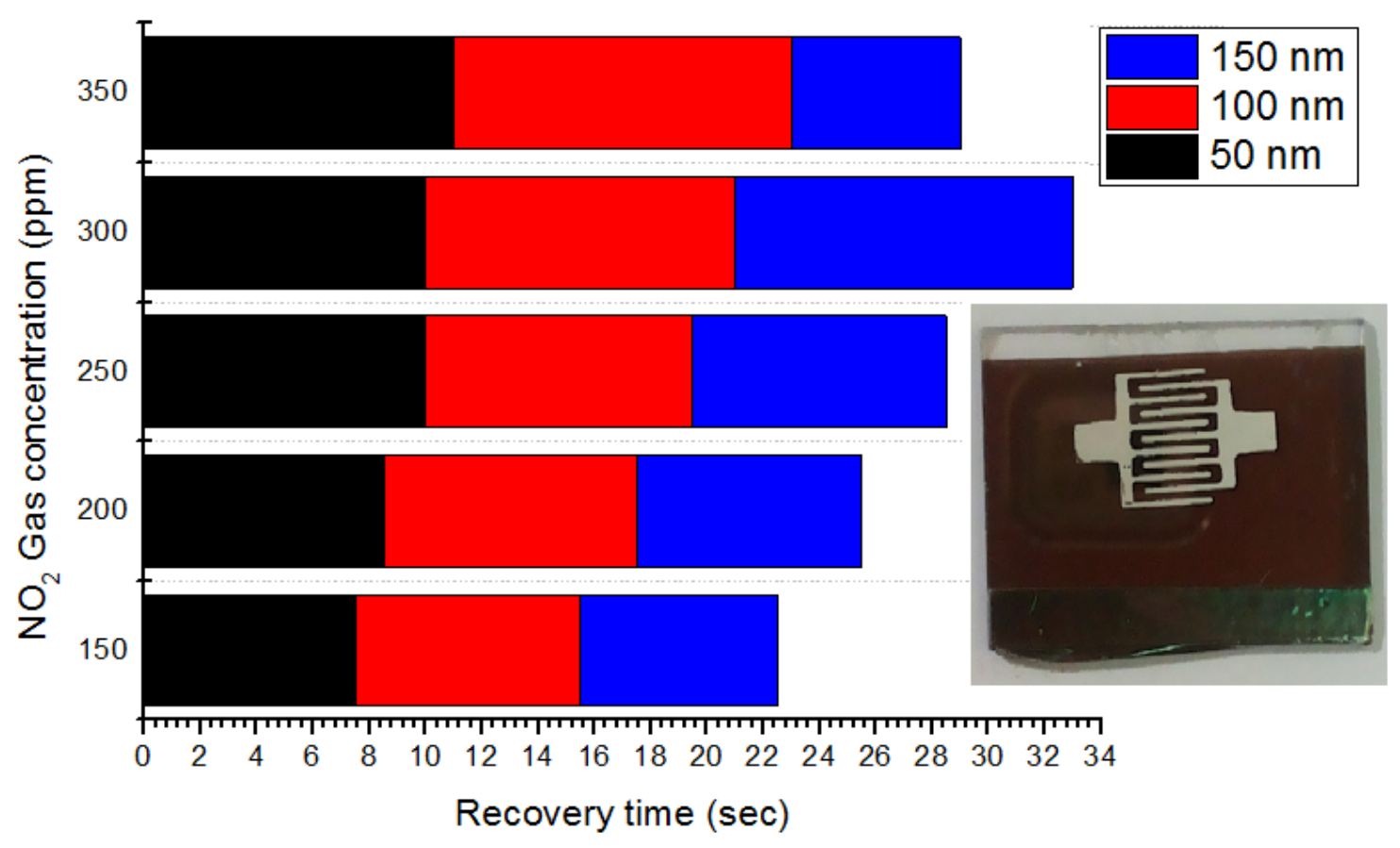

Figure 7: Recovery Time of NiO Films for Different Concentrations of $\mathrm{NO}_{2} \mathrm{Gas}$ and Different Thicknesses at $150 \circ \mathrm{C}$ Operating Temperature 


\section{CONCLUSIONS:}

Different thickness of $\mathrm{NiO}$ nano structures films are successfully prepared using RF reactive magnetron sputtering. The polycrystalline structure film with cubic structure of $\mathrm{NiO}$ film is formed and the films show growth along the (200) direction for all prepared films with Rod like nano structure growth. The transmittance in the UV and VIS regions results the value of optical Eg decreasing with thickness increases. The $\mathrm{NiO}$ films of $150 \mathrm{~nm}$ thickness show the maximum sensitivity is $67 \%$ for $\mathrm{NO}_{2}$ gas of $350 \mathrm{ppm}$ gas concentration obtained at operation temperature $150^{\circ} \mathrm{C}$.

\section{REFRENCES}

[1] E. Fujii, A. Tomozawa, H. torii and Takayama "Thickness Influence On The Synthesis Of Metal Oxide NiO Using RF- Magnetron Sputtering “ japan. j. appl. 35, 328-330, (1996).

[2] K. Youshmura, T. Miki, S. Tanemura " nickel oxide electrochromic thin films prepared by reactive DC magnetron Sputtering" jap.j.Appl.phys.34, 24402446, (1995).

[3] M. Kitao, K. Izawa, K. Urabe, T. Komatso, S. Knwano and S. Yamada "Electro chromic properties of sputtered nickel-oxide films "Jap. Appl. phy.33, 6656-6662, (1994).

[4] R. Tsu, L. Esaki, R, Ludeke," road to quantum boxes" physic. Rev. 23 -763, (1996).

[5] Praveen K. Sekhar, Eric L. Brosha, Rangachary Mukundan, and Fernando H. Garzon" Chemical Sensors for Environmental Monitoring and Homeland Security" The Electrochemical Society Interface, Winter 2010.

[6] P. pramank, S. Bhattachraga," A Chemical Method for the Deposition of Nickel Oxide Thin Films “ J. Electrochemecal.soc.137, 3869, (1990).

[7] L. D. Kadam, C .H. Bhosal, P. S. Patil," Versatility of Chemical Spray Pyrolysis Technique" Tr.j.phy.21, 1037, (1997).

[8] Larry L. Hench and Jon K. West "The sol-gel process“" Chem. Rev., , 90 (1), pp. 33-72, (1990).

[9] Mario birkhols " thin film analysis by X-ray scattering “, willey, Vhc. (2006).

[10] H. W. Ryu, G. P. Choi, W. S. Lee and s. park j. "Effects of Substrate Temperature and Oxygen Pressure on Crystallographic Orientations of Sputtered Nickel Oxide Films" mater sci.lett.39, 4375-4377, (2004).

[11] B. D. Cuttity and S. R. stock, "Element of X-ray diffraction , 3rd Ed. (2001).

[12] Q. Simon, D. Barreca, A. Gasparotto, C. Maccato, E. Tondello, C. Sada, E. Comini, G. Sberveglieri,
M. Banerjee, K. Xu, A. Devi, R. A. Fischer " $\mathrm{CuO} / \mathrm{ZnO}$ nanocomposite gas sensors developed by a plasma-assisted route" Phys.Chem 13, 2342, (2012).

[13] N. Lee, Sh. Kim, Kakani, "Effect of film thickness on the structural morphological and optical properties of nanocrystalline $\mathrm{ZnO}$ films formed by RF magnetron sputtering " thin solid films. 494519, (2010).

[14] A. J. Varkey and A. F. Fort "Solution growth technique for Deposition of nickel Oxide thin films, Thin Solid Films" vol. 235, 47-50, 1993.

[15] J. S. E. M. Svensson and C. G. Granqvist "Electrochromic Hydrated nickel oxide Coatings for energy efficient windows: Optical properties and coloration The mechanism" Applied Physics Letters, vol. 49, no. 23, 1566, (2003).

[16] S. Yamada, T. Yoshioka, M. Miyashita, K. Urabe, andM. Kitao" Electrochromic Properties of sputtered nickel oxide films" Journal of Applied Physics, vol. 63, No, 6, 2116-2119, (1988).

[17] M. boscarino, Ferroni, D. comini, E. gnani, V. guidi, V. martielli, G. nellii, $\mathrm{P}$. rigato, V. sberveglieri, G,: "Selective sublimation processing of a molybdenum-tungsten mixed oxide thin film" 58. 289, (1999).

[18] K. M. Dooley, S.Y. Chen, J. R. H. Ross, J. Catal.” CHEMICAL CAPPING SYNTHESIS OF NICKEL OXIDE NANOPARTICLES AND THEIR CHARACTERIZATIONS STUDIES “ 145- 402, (1994).

[19] A. Iida and R. Nishikawa, "A thin film of a Ni-NiO heterogen- Eoussystem for an optical recording medium" Japanese Journal of Applied Physics, vol. 33, 3952- 3959, (2006).

[20] E. Fujii, A. Tomozawa, H. Torii and R. "Takayama" Effects of Substrate Temperature and Oxygen Pressure on Crystallographic Orientations of Sputtered Nickel Oxide Films" Jpn. J. Appl. Phys.35, 328-330, (1996).

[21] J. Huang and Q. Wan "Gas Sensors Based on Semiconducting Metal Oxide One-Dimensional Nanostructures" Sensors (Basel), 9(12), 99039924, 2009.

[23] D. Delia Puzzovio “ Surface Interaction Mechanisms in Metal-Oxide Semiconductors for Alkane Detection “ A Thesis in Universita Degli Studi Di Ferrara, 2008.

[24] A. R. Balu, V.S. Nagarethinam ," Nanocrystalline NiO Thin Films Prepared by a Low-Cost Simplified Spray Technique Using Perfume Atomizer"' Journal of Electron Devices, Vol. 13, pp. 920-930, (2012). 
[25] Arwaa Fadil, "Structural and Morphological Studies of NiO Thin Films Prepared by Rapid Thermal Oxidation Method" IJAIEM, volume 2, Issue 1, Jan.(2013).

[26] H. Long Chen, Y. Ming Lu and W. Sing Hwang, Materials Transactions, Vol. 46, No. 4 - pp. 872 to 879, (2005).

[27] M. Batzill and U. Diebold,"The Surface and Materials Science of Tin Oxide", Progress in Surface Science, Vol. 79, PP. 47-154, (2005).

[28] G. D. Cãnizares "Nanostructured Nickel Oxide Thin Films Grown by Reactive RF Magnetron Sputtering Thesis UNIVERSIDAD AUTONOMA DE MADRID May 2014.

[29] N. Barsan and U. Weimar" Fundamentals of Metal Oxide Gas Sensors" IMCS- The 14th International Meeting on Chemical Sensors (2012).

[30] A. Muhammad, R, Mahfujur, J. M. Don, Coburn, Nadia, D, Danilo, V. Johannes G., Dowling, Denis P. "Deposition and Characterization of NiOx Coatings by Magnetron Sputtering for Application in Dye-Sensitized Solar Surface and Coatings Technology“204 (16-17): 2729-2739. 2011.

[31] M. Tachikawa and M. Yamaguchi, Film thickness dependence of dislocation density reduction in GaAs-on-Si substrates, Appl. Phys. Lett. 56, 484 (1990).

[32] B. Subramanian, M. Mohamed Ibrahim, V. Senthilkumar, K. Murali, V.S. Vidhya, C. Sanjeeviraja, M. Jayachandran "Optoelectronic and electrochemical properties of nickel oxide (NiO) films deposited by $\mathrm{DC}$ reactive magnetron sputtering” Physica, 403 - 4104-4110, (2008)

[33] J. Bachmann, A. Zolotaryov, O. Albrecht, S. Goetze, A. Berger, D. Hesse, D. Novikov and K. Nielsch. "The stoichiometry of nickel oxide lms prepared by ALD. Chemical Vapor Deposition" 17(7-9):177180, 2011

[34] Y. Ashok Kumar, A. Sivasankar and P. Sreedhara "Influence of oxygen partial pressure on the structural, optical and electrical properties of $\mathrm{Cu}$ doped NiO thin films" Phys. Scr. 87 - 015801 (5pp), (2013) .

[35] B. Shweta, A. Acharya ," Effect of copper doping on the change in the optical absorption behavior in $\mathrm{NiO}$ thin films", journal of Renewable Energy,46,43-48,(2012)

[36] S.C. Chen a, T.Y. Kuo b, Y.C. Lin a, S.W. Hsu a, H.C. Lin b" Effect of Palladium Content on Microstructures, Electrical and Optical Properties of NiO Films by RF Sputtering" JASCOThin Solid Films 549 - 50-53, (2013).
[37] F. S. Hashim, K. H. Mohsin, "Effect of Li Doping on Structure and Optical Energy Gap of $\mathrm{NiO}$ Films Prepared by Sol-Gel Technique" JOURNAL OF KUFA - PHYSICS Vol.7/ No.1 (2015). 